\title{
SABERES PEDAGÓGICOS: DESAFIOS DOCENTES DO SÉCULO XXI
}

\author{
SABERES PEDAGÓGICOS: DESAFÍOS DOCENTES DEL SIGLO XXI
}

PEDAGOGICAL KNOWLEDGE: TEACHING CHALLENGES OF THE XXI CENTURY

Luana MONTEIRO ${ }^{1}$

RESUMO: A presente resenha propõe a apresentação do e-book "Saberes Pedagógicos: Perspectivas \& Tendências", organizado por Alexandre Shigunov Neto e Ivan Fortunato, publicado pelas Edições Hipótese no ano de 2018. A leitura crítica da obra destaca o diálogo entre os seis capítulos que refletem sobre os saberes pedagógicos explorados cotidianamente na prática docente, relacionando os contextos concretos e atuais, inquietações e problemáticas da profissão professor. Ainda, indo mais além das particularidades da prática docente, os autores desenvolvem reflexões críticas sobre a formação inicial e continuada de professores, relacionando seus aspectos relevantes, emblemáticos e os impactos no exercício dessa profissão.

PALAVRAS-CHAVE: Saberes pedagógicos. Prática docente. Formação inicial e continuada.

RESUMEN: La presente reseña propone la presentación del e-libro "Saberes Pedagógicos: Perspectivas \& Tendencias", organizado por Alexandre Shigunov Neto e Iván Fortunato, publicado por las Ediciones Hipótesis en el año 2018. La lectura crítica de la obra destaca el diálogo entre los seis capítulos que reflejan sobre los saberes pedagógicos explotados cotidianamente en la práctica docente, relacionando los contextos concretos y actuales, inquietudes y problemáticas de la profesión profesor. A pesar de que, más allá de las particularidades de la práctica docente, los autores desarrollan reflexiones críticas sobre la formación inicial y continuada de profesores relacionando sus aspectos relevantes, emblemáticos y los impactos en el ejercicio de esa profesión.

PALABRAS CLAVE: Saberes pedagógicos. Práctica docente. Formación inicial y continuada.

ABSTRACT: The present review proposes the presentation of the e-book "Pedagogical Knowledge: Perspectives \& Trends", organized by Alexandre Shigunov Neto and Ivan Fortunato, published by Edições Hipótese in 2018. The critical reading of the work highlights the dialogue between the six chapters that reflect on the pedagogical knowledge explored daily in the teaching practice, relating the concrete and current contexts, concerns and problems of the teacher profession. Still, going beyond the particularities of the teaching practice, the authors develop critical reflections on the initial and continued formation of teachers relating their relevant, emblematic aspects and the impacts in the exercise of this profession.

${ }^{1}$ Universidade Federal de São Carlos (UFSCAR), Sorocaba - SP - Brasil. ORCID: < https://orcid.org/00000003-2881-1246>. E-mail: luana.monteiro13@etec.sp.gov.br 
KEYWORDS: Pedagogical knowledge. Teaching practice. Initial and continued education.

As escolas são lugares complexos, cuja missão é educar grupos heterogêneos de alunos, bem como constituir-se como espaços pedagógicos. Nessa complexidade do espaço escolar, como a figura do professor, peça-chave nessas instituições, compreende seu papel e reconhece sua atuação? Quais são as necessidades, perfis profissionais que essas escolas modernas requerem? O e-book "Saberes Pedagógicos: Perspectivas \& Tendências", organizado por Alexandre Shigunov Neto e Ivan Fortunato, publicado pelas Edições Hipótese em 2018, apresenta algumas possíveis respostas a tais inquietações. O livro conta com seis capítulos, fundamentados em um referencial teórico de considerável valor como Donald Schön, Libâneo, Morin, Nóvoa, Pimenta, Sacristán, Perrenoud, Tardif, entre outros. Em cada capítulo, seus autores propõem diálogos e reflexões sobre os saberes pedagógicos, saberes que são explorados cotidianamente na prática docente, assim como são constituídos durante a formação docente inicial e continuada.

Para tanto, no primeiro capítulo, abrindo um rico diálogo, a autora Rosa $\mathrm{M}^{\mathrm{a}}$ Esteban Moreno apresenta uma análise sobre modelos de orientação profissional em províncias da Espanha, apresentando uma breve abordagem histórica, compreendendo desde o ano de 1908, com as práticas de autoanálises, informação profissional, até o presente momento com a valorização da educação emocional, orientação vocacional, atendimento às necessidades especiais, diversidades e inclusão. Dentro dessa perspectiva histórica, em diferentes épocas foi evidenciada a atuação dos orientadores, suas relações, comportamentos e demandas em relação aos ambientes institucionais, aos alunos, familiares, mudanças políticas, econômicas, culturais e sociais, bem como as inovações, competências necessárias e exigências de sua atuação.

Em suas considerações finais a autora retoma os parágrafos iniciais para apontar reflexões em relação à formação inicial docente. Profissionais docentes em formação precisam desenvolver as habilidades do século XXI para que sejam capazes de atender as demandas educacionais desse século, seus conflitos, diversidades e desafios.

Paralelo ao defendido por Rosa $\mathrm{M}^{\mathrm{a}}$ Esteban, o segundo capítulo, produzido por José Luiz Medina, também aponta as influências das transformações dos sistemas de ensino e das sociedades na atuação docente, bem como um novo currículo pautado em competências. Nessas transformações, os profissionais docentes passem por mudanças em suas práticas em 
seus saberes. Par refletir sobre essa questão, o autor propõe uma reconceituação dos saberes docentes.

Assim, juntamente com o posicionamento defendido por Schon (1992) e Perrenoud (2004), o autor contesta o pensamento do trabalho docente ser compreendido como uma racionalidade técnica, instrumental, de orientação positivista. A atuação docente é pautada em saberes pedagógicos, conhecimentos práticos desenvolvidos durante sua caminhada em diferentes e complexas experiências, situações, crenças, configurando um processo de racionalidade reflexiva.

Nesse caminho, o autor também enfatiza a preocupação com a formação que ocorre dentro das universidades que adotam currículos como disciplinas fragmentadas, voltadas à produção de conhecimento formal, enquanto não atuam no desenvolvimento de pesquisas, investigações sobre a prática e saberes pedagógicos. É necessário, portanto, que as instituições formadoras de professores desenvolvam currículos pautados também na prática pedagógica, nos saberes docentes para uma formação de professores efetiva.

Posteriormente, o terceiro capítulo, "Volta Pedagogia", escrito por Idália Sá Chaves, traz uma reflexão crítica sobre as práticas pedagógicas tecnicistas e positivistas. Para a autora, as instituições de ensino formal reduzem a vida e a cultura dentro do processo educacional baseado apenas em teorias. Contrariando essa prática, com base em Bronfenbrenner (1979), Idália coloca a abordagem ecológica das práticas educativas, que possibilita a esse processo uma caráter mais humano. Assim como nos dois primeiros capítulos, a autora também aponta a necessidade de uma formação docente pautada na investigação dos saberes pedagógicos, práticas reflexivas e críticas, ou seja, uma prática efetivamente pedagógica, referenciando assim o título: Volta Pedagogia!

O quarto capítulo, proposto por Maria Amélia Santoro Franco, está diretamente relacionado aos diálogos apresentados nos capítulos anteriores. A autora propõe reflexões conceituais sobre os saberes pedagógicos, visto que entre diversas discussões sobre o tema na atualidade, a expressão saberes pedagógicos passou a ser confundida com fazeres. Assim, há uma diferença entre o saber, a informação e o conhecimento, bem como a relação entre o sujeito e o saber. Os saberes são desenvolvidos a partir da relação do sujeito com seu meio, compreendendo-o assim como indissociável do sujeito, visto que é a partir desse que o saber é construído.

Ao registrar situações vivenciadas por docentes para refletir sobre o saber, foi possível, para a autora, verificar diferentes questões relacionadas ao saber pedagógico, saber profissional e o saber didático. Porém, esses são saberes inseparáveis e constantemente 
explorados de acordo com as situações experimentadas pelos sujeitos. Ainda nessas experiências, a autora pontuou que os processos formativos docentes não podem ser pautados em receitas, mas na reflexão dos saberes docentes, superando práticas tecnicistas e mecânicas.

O quinto capítulo, desenvolvido por Lívia Brisolla, apresenta uma questão inquietante: o que se espera de um professor? A prática docente é baseada em seus saberes pedagógicos. Por sua vez, quando esses são investigados, não podem ser limitados a discussões sobre sala de aula, ou até mesmo ser compreendido como fórmulas ou procedimentos. Os saberes que constituem o trabalho docente devem ser compreendidos na sua complexidade, como um processo de constante reflexão realizado durante a carreira docente.

Durante a formação inicial e continuada, as discussões dos saberes pedagógicos são necessárias para que futuros professores possam refletir sobre sua prática, bem como o que se espera de sua atuação. Também dentro dessa discussão, a autora tece a crítica aos saberes pedagógicos serem considerados como competências, reduzindo-os em procedimentos, métodos e teorias, aproximando-os às práticas tecnicistas, que não priorizam os processos reflexivos. Para Brisolla, os saberes pedagógicos são processos construídos desde a formação inicial e permanecem em constante atualização em sua formação continuada durante o exercício da profissão docente. São saberes da experiência, saberes do conhecimento e saberes pedagógicos, constantemente relacionados com a prática social docente. A atuação do professor relacionadas com seus saberes dentro de um constante processo de formação é o que se espera em sua prática

Por fim, o último capítulo, apresentado por Ivan Fortunato, ao dialogar com os capítulos anteriores, propõe a reflexão sobre três saberes pedagógicos. Esses saberes levados à reflexão foram relacionados durante experiências com a formação inicial de alunos do curso de licenciatura em física do IFSP, campus Itapetininga, bem como situações presentes em sua carreira docente, que também são relatadas como forma de enriquecer o texto e exemplificar os saberes pontuados.

O primeiro saber apontado: ser professor é uma profissão, coloca em questão temáticas presentes no exercício da prática docente, como o reconhecimento da docência como uma profissão e a precarização desse trabalho. O exercício docente ocorre dentro de um sistema complexo, institucionalizado, carregado de compromissos sociais, políticos, econômicos e culturais, cobranças e valores, o que faz com que sua função seja considerada como uma profissão, embora situações que levem a sua precarização, quando o trabalho docente é considerado como "bico", ou atividade esporádica para complementação de renda familiar. 
Na prática cotidiana, o professor precisa considerar seu trabalho como uma profissão, compreendendo seus valores, responsabilidades e compromissos.

Respectivamente, o segundo saber: reconhecer as contingências gerais e situacionais da profissão, introduzido por uma epígrafe de Tardif, trançando um paralelo com as palavras desse escritor, o saber docente se identifica além da sala de aula, dos muros da escola, bem como nas contingências dessa profissão, as quais vão desde a falta de recursos básicos, até entraves de programas curriculares e políticas educacionais. Em contribuição com os autores dos capítulos anteriores, a formação inicial necessita ter a preocupação de apresentar a realidade do cotidiano escolar, da sala de aula, proporcionando discussões, reflexões sobre suas contingências e situcionalidades.

Para o último saber: aprender com e pela própria experiência, ou aprender consigo mesmo, o autor defende que as práticas formativas como a graduação, pós-graduação, cursos, palestras, etc., são compreendidas como práticas de formação exterior. O saber docente, por sua vez, necessita também da formação interior, o que denomina como auto formação, ou seja, um momento em que o sujeito seja capaz de pensar, refletir sobre suas próprias ações, ideologias, concepções e contradições, mesmo que não seja uma tarefa fácil.

De forma geral, o livro traz um rico diálogo entre seus capítulos, proporcionando uma reflexão sobre os saberes pedagógicos em situações práticas do trabalho docente, enfatizando a preocupação em relação à formação de professores, inicial e continuada, propondo que esses momentos sejam permeados de investigações e reflexões sobre a articulação dos saberes pedagógicos para um efetivo exercício da docência no século XXI.

\section{REFERÊNCIAS}

HIGUNOV NETO, Alexandre. FORTUNATO, Ivan (org.). Saberes pedagógicos:

perspectivas \& tendências. São Paulo: Edições Hipótese, 2018. p. 97.

\section{Como referenciar este artigo}

MONTEIRO, Luana. Saberes pedagógicos: desafios docentes do século XXI. Doxa: Rev. Bras. Psico. e Educ., Araraquara, v. 20, n. 1, p. 125-129, jan./jun., 2018. e-ISSN: 2594-8385. DOI: $10.30715 /$ rbpe.v20.n1.2018.11091 